\title{
Improving Classroom Engagement using Enhanced Teaching Methods
}

\author{
Brian Keegan, Bianca Schoen \\ School of Computing, Dublin Institute of Technology, Ireland
}

\begin{abstract}
Third level student engagement in the classroom can be difficult for a number of reasons. Putting the content aside, factors include the duration of the class, size of the class, and time of day. Teacher directed learning with enhanced teaching techniques can be used to improve motivation. The teacher is central to the direction of technique used and should adapt to the environment. Introducing classroom activities can be seen to improve student engagement and to reinforce key components. Teaching a technical discipline possess additional challenges in that the requirement to use technology in the classroom may not be feasible due to available infrastructural services. However, many students now possess mobile technology which allows them to participate in simple short classroom quizzes. The classroom quiz provides an opportunity to open discussions regarding question specifics. In addition to this it can be shown that improving participation in the classroom can improve motivation and performance in a subject overall. This paper will assess the performance of students studying a networking module whilst undertaking year 3 of a 4 year honours degree in computing.
\end{abstract}

\section{Introduction}

The traditional method of teaching requires that the lecturer should understand enough about a subject in order to adequately convey the information. The traditional method of direct instruction [1] is often referred to as "The Sage on the Stage". A particular teaching method is used in order to deliver the information directly. This method often is useful for teaching students with no prior knowledge of a subject [2]. Student learning is normally in the form of visual, audio and kinaesthetic learning. A progressive instructional strategy as outlined by the authors of [3] puts the lecturer more into the role of course designer, discussion facilitator, and coach. The student takes on more of a role of active learner, discovering the subject of the course independently.

As we move from a traditional approach to learning, toward blended learning and incorporation of a "flipped" classroom [4], an important question should be asked: How do we encourage students to engage in the classroom?
Student engagement involves not just their interaction in the classroom but also their interaction with online learning materials in a blended learning environment. Student performance is normally measured based on assessments [5]. However, this does not highlight their engagement with the material or their own perception of engagement. Students who are motivated will show higher attendance, pay better attention and will volunteer to answer questions. Students should be motivated from a number of different sources to enhance their learning experience [6], [7]. Enhanced learning techniques such as using an opening "hook" to draw the class in can be used. It is recommended that a number of techniques (quizzes, questions on the board, questioning and discussions, visual aids etc) can be used throughout the class to aid student motivation [8]. More simple techniques such as summarizing the lecture and providing an overview of the next lecture are also encouraged [9]. According to [10] attention cycles should be accommodated using studentcentered enhanced lecture techniques. Student motivation can be increased by introducing a quiz element into classroom learning [3-K, J-L]. An appropriately timed quiz during lessons can help students focus on the material being delivered and motivate them to engage with the material. As well as improving motivation [13], overall student performance can be increased by reducing the amount of cramming normally associated with end of year exams.

The main objective in carrying out this work is to improve student motivation and to increase student participation through an entire module. The work highlights the difference between the current (standard) teaching approach and one that facilitates student interaction. The interaction introduces a dialogue between students and lecturer which may have been previously suppressed due to lack of motivation (from students or teacher). The purpose of the in class quiz is not to simply assess the students ability but instead to provide an opportunity to give feedback and engage in discussion. Therefore, the emphasis should not be on their ability to answer the questions correctly but rather on their willingness to participate. 


\section{Literature Review}

According to Braun et al. [11] certain groups of students (mainly first year and second year) lack the same level of motivation as final year students. As such, lecturers of these courses have to find more effective strategies to motivate students. The authors have identified to following as key areas which need to be addressed by the lecturer;

- Class preparation

- Student punctuality for class attendance

- $\quad$ Participation in class activities

In order to address these issues, Braun et al have recommended using an easy to grade quiz that students should be able to answer providing they are familiar with the course work. The paper suggests that the student should have read the work in advance, however, it is possible to use the activity to test students on keys points during an actual lecture. Although testing students on key points during a lecture is desirable (and more beneficial), this removes the requirement of preparation in attendance. In [12], the authors suggest that the aim of the quiz should be to check what the students have learned. The authors also advise that the test should be as accessible as possible as difficult test can have a negative effect. Furthermore, the authors stress that the questions should not be ambiguous or confusing to the students.

Williams and Williams [13] support the work of Braun et al by identifying 5 key ingredients for improving student motivation.

- Students

- Teacher

- Content

- Method/Process

- Environment

Williams and Williams discuss how very little student learning can occur without consistent motivation and note that all of these strategies should be used as often as possible. However, they also note that aspects of any of the five components could contribute to and/or hinder motivation. As such, lectures should be selective about which elements they wish to change/enhance and closely watch the outcomes of the student motivation. The authors use the 5 key ingredients as guidelines and do not place an emphasis on any one ingredient.

A major challenge with delivering modules which rely on practical engagement and understanding is the environment. For the module addressed (networking) in this study, this is particularly true. The practical work is experienced in a lab. However, there is lecture time associated which takes place in a classroom. The environment provided for lectures does not allow for practical sessions (students would need a considerable amount of dedicated hardware).
Referring to the 5-Key Ingredients outlined above it can be seen that the environment would have to make allowances in favour of change in method/process. As a result, the content would remain the same, however, it is envisaged that the student and teacher "ingredients" would improve.

According to [14] learning outcomes largely influence the teaching and assessment activities. Figure 1 below illustrates how this interaction takes place which can be used as a general framework for teaching. The focus is on learning outcomes which are supported by teaching activities and assessment tasks. For this study the learning outcomes would align with existing module descriptors. The teaching and learning activities would be a combination of teacher and peer managed. Assessment of student performance would remain through examinations and continuous assessment. However, assessment of student motivation and engagement can now be tracked through use of quiz activities and frequency of access to material.

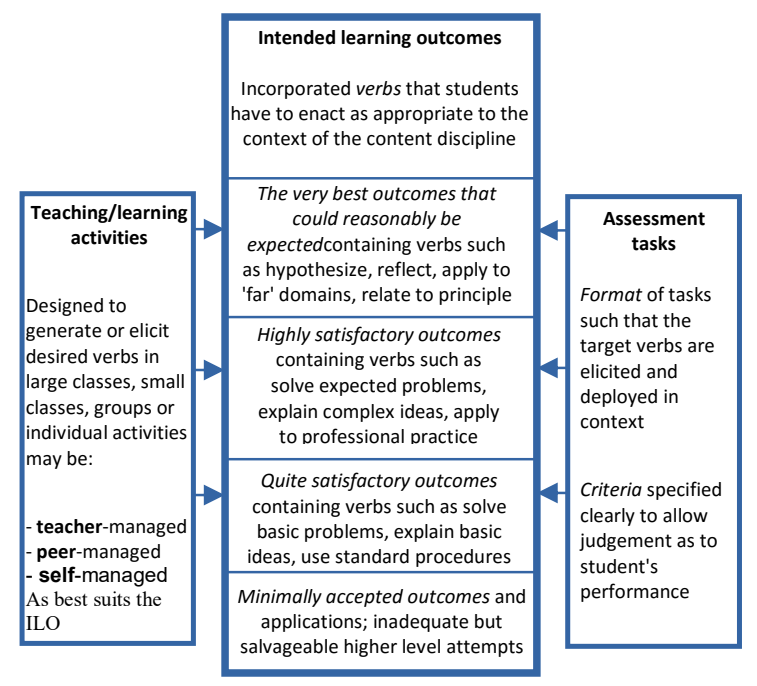

Figure 1. Learning outcomes aligned with teaching assessment [14]

By introducing a classroom quiz based on learning outcomes this framework can still be maintained and help to improve student motivation and engagement.

In order to determine the success of the quiz and overall engagement feedback is required from the students. To accomplish this, students are surveyed regarding their participation, satisfaction and engagement with the module. As a basis for the survey the Irish Survey of Student Engagement [15] was consulted to extract appropriate questions and format. The survey provides quantitative feedback which is presented in the discussion and findings section.

Assessing student learning should use applied knowledge tasks [16]. Using multiple-choice 
multiple-answer questions can be used for applied knowledge assessment which are often used for computerised assessment. This format allows for remote assessment and instant feedback. However, Davies [17] argues that computer assessment should be more than just multiple-choice tests for it to be credible. The purpose of the computer aided assessment in this study is used to supplement practical exams and written exams. The computer based assessment accounts for a portion of the overall grade.

\section{Research Methodology}

The study was carried out in two phases with a group of 46 students studying network technology in their penultimate year of an honours degree program. Students engage in two hours of lectures and 2 hours of practical labs over a single 12 week semester. Continuous assessments (CA) are given at week 7 and week 11. The continuous assessment is in the form of a multiple choice multiple answer exam. The main difference between the phases is that the classroom quiz provided an opportunity to engage in discussion relating to correct and incorrect answers. The quiz activity allows for feedback to be given to the entire class thus benefiting entire group.

\subsection{Phase 1}

Phase 1 utilised the traditional method of classroom lectures supported with labs and took place from week 1 to week 7 inclusive. Lectures consisted of slides which can facilitate discussion throughout the lecture. Students should have carried out self-study in addition to using online material provided by NetAcad[18]. Student access to the online material was tracked through records of weekly logins. Lecture notes are hosted on Webcourses (an online learning and teaching resource provided by [19]) and were available to download each week. Webcourses statistics tracking was enabled which allows tracking of file access and downloads. Students were given a continuous assessment (CA01) to examine their skills at the end of phase 1. A survey was conducted before the exam.

\subsection{Phase 2}

The procedure was the same as phase 1 with the addition of a classroom quiz during lectures. Phase 2 took place from week 8 to week 12 inclusive. The quiz consisted of $3-5$ multiple choice/answer questions using software that facilitates real-time questioning, Socrative [20] and mobile technology (smart-phones or laptops). The quiz was timed for delivery at the end of each major section (approximately every 20 minutes). Students were again given a continuous assessment (CA02) to examine their skills.

Survey questions were based on a study carried out for the Irish Survey of Student Engagement, 2013 [15]. Student responses were graded on a scale $1-5$ with the general format as follows;

$\begin{array}{ll}\text { 1. } & \text { Never } \\ \text { 2. } & \text { Sometimes } \\ \text { 3. } & \text { Often } \\ \text { 4. } & \text { Very often } \\ \text { 5. } & \text { Don't know. }\end{array}$

Student participation in the survey was high with $94 \%$ of the students engaging (43 out of 46 ). The questions can be seen in Table 1 below.

Table 1. Post quiz survey questions

\begin{tabular}{|c|c|}
\hline Q1 & $\begin{array}{l}\text { How often have you asked questions in class } \\
\text { or lab? }\end{array}$ \\
\hline Q2 & $\begin{array}{l}\text { How often have you worked hard to master a } \\
\text { difficult concept? }\end{array}$ \\
\hline Q3 & $\begin{array}{l}\text { How often have you attended class without } \\
\text { completing preparatory work? }\end{array}$ \\
\hline Q4 & $\begin{array}{l}\text { How often have you attended this module } \\
\text { without completing the preparatory work? }\end{array}$ \\
\hline Q5 & $\begin{array}{l}\text { How often do you access the online course } \\
\text { material in NetAcad? }\end{array}$ \\
\hline Q6 & $\begin{array}{l}\text { How often do you access learning material } \\
\text { for this module other than the supplied } \\
\text { material? }\end{array}$ \\
\hline Q7 & How prepared are you for this exam? \\
\hline Q8 & $\begin{array}{l}\text { Have you completed many of the WAN } \\
\text { Technologies chapter exams? }\end{array}$ \\
\hline Q9 & $\begin{array}{l}\text { Do you think the lectures adequately cover } \\
\text { the Cisco course material? }\end{array}$ \\
\hline Q10 & How interested are you in this module? \\
\hline \multicolumn{2}{|r|}{ Additional questions for Phase 2} \\
\hline Q11 & How satisfied where you with the CA? \\
\hline Q12 & $\begin{array}{l}\text { How beneficial did you find the classroom } \\
\text { quiz? }\end{array}$ \\
\hline
\end{tabular}

\section{Findings and Discussion}

In Figure 2, student responses to the phase 1 pretest survey are displayed. An interesting return from this was the student perception on how often they view online material (Q5). From the results, approximately $27 \%$ said they never access the online material.

Figure 3 represents the actual student usage of the online resource and indicates a contradictory result. Before the lab exam in week 7, approximately 50\% of students had not accessed the content since week 1 (week 1 of teaching started on September $15^{\text {th }}$ ). In addition to this, students were asked if they access other course material for which approximately $15 \%$ 
said never. According to Web Courses statistics tracking, students had never downloaded lecture notes.

Questions 9 (Do you think the lectures adequately cover the Cisco course material?) and 10 (How interested are you in this module?) were graded on the same 1-5 scale and were intended for instructor feedback. The expectation here, given the low interaction with the online material, was that there would be an even spread of responses. On the contrary, the results were considerably positive. Over $75 \%$ said that the lectures were prepared or very prepared and approximately $88 \%$ of students said they were interested to some degree in the subject. This would indicate a high level of enthusiasm for the subject.

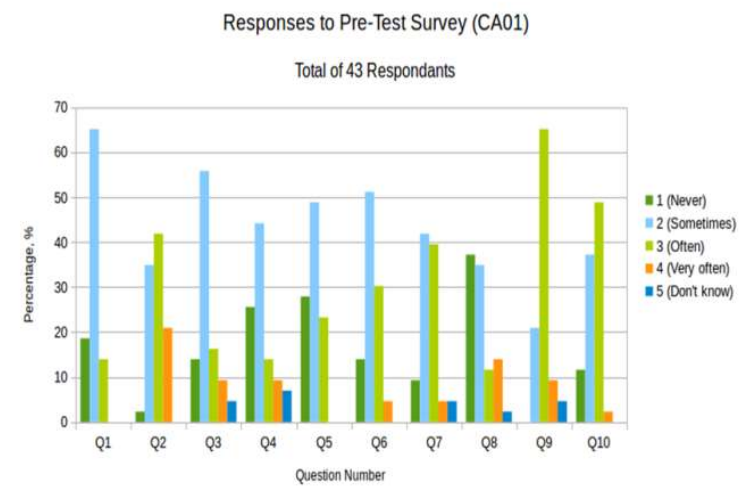

Figure 2. Responses to CA01 pre-test survey

Tracking Student Usage of NetSpace

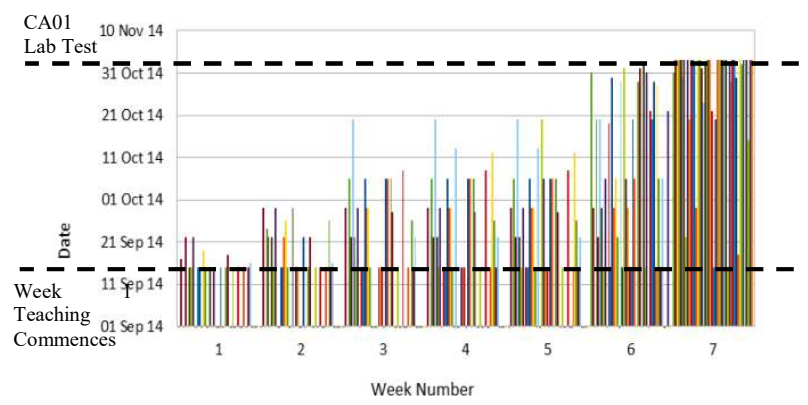

Figure 3. Tracking student access to Cisco NetAcad content (CA01)

The graph in Figure 3 represents student access to online material in NetAcad tracking. A clear increase in the level of access in week 7 is apparent. This indicates that student engagement with online material is low with a significant increase before the assessment in week 7. However, usage statistics from WebCourses indicated that there was no material for this module downloaded (i.e. class lecture notes).

In phase 2 students engaged in a short classroom quiz. Participation in the quiz was anonymous with the focus on providing feedback to questions answered. Students could see the percentage of correct or incorrect responses for the entire class as they progressed. This facilitated a discussion on the correct (an incorrect) answers and increased student engagement. In Figure 4, responses to the pre-test survey for CA02 are shown. In addition to previous questions the following were included;

- Q11: How satisfied where you with the CA? Response: 1: 5\%, 2: 30\%, 3: 47\%, 4: 12\%, 5: 0\%

- Q12: How beneficial did you find the classroom quiz

Response: 1: 0\%, 2: 23\%, 3: 56\%, 4: 9\%, 5: 2\%

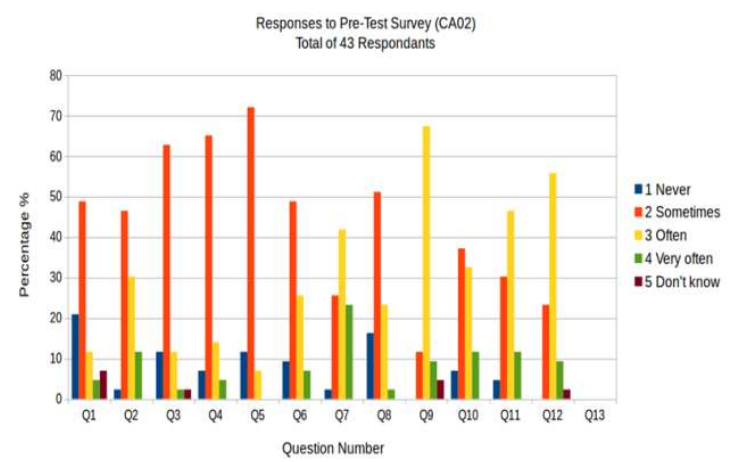

Figure 4. Responses to CA02 pre-test survey

After tracking the student access to online material again, it can be seen that interaction is once more low until the week of the continuous assessment. Figure 5 shows a similar trend to Figure 3. As in the previous phase, WebCourses indicated that there was negligible download activity.

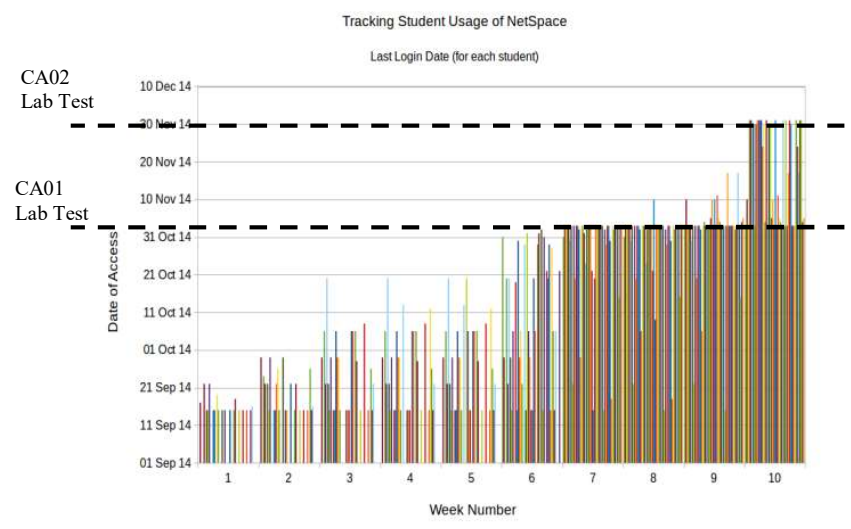

Figure 5. Tracking student access to Cisco NetAcad content (CA01 and CA02)

Student tracking of engagement of online material shows an obvious trend on how students prepare last minute for an exam. Table 2 shows the student performance when compared between phase 1 and phase 2. The two most significant findings from this comparison are the time spent answering questions and the improvement in score. After phase 2 the students spent longer answering questions. The 
payoff for this was the improvement in all student performance. This occurred not just at the average but also for the top performing students.

Table 2. Comparing student performance from phase 1 to phase 2

\begin{tabular}{|c|c|c|}
\hline & CA01 & CA02 \\
\hline Average Time & 32 mins & 42 mins \\
\hline Average Correct & 31.91 & 38.76 \\
\hline Average Incorrect & 11.59 & 9.52 \\
\hline High Score & 88 & 100 \\
\hline Low Score & 24.67 & 16 \\
\hline Mean Score & 66.17 & 78.89 \\
\hline Standard Deviation & 18.52 & 18.19 \\
\hline
\end{tabular}

\section{Conclusions}

The results were surprising in that student perception on their level of interactivity can be considered higher than actuality. Clearly students did not access the material as much as they believed they did. However, from the survey student interest is quite high. It could be argued that students are accessing content on the subject from alternative learning resources not tracked. For example, students may be using an alternative learning resource or could be distributing notes via some other means, such as dedicated Facebook groups. This could be investigated further by refining the survey to ask more direct questions on this matter.

Phase 2 involved using an interactive quiz (ungraded) in the classroom as well as a lab quiz for continuous assessment. Feedback from phase 2 was positive in terms of the classroom quiz. The format of the quiz uses $2-3$ multiple choice questions via Socrative [20]. The quiz takes time to set up and timing of delivery is crucial. Timing should allow for a number of factors;

- Ideally a quiz should be delivered after each major or new topic or after approximately 20 -30 mins.

- The quiz should allow time for discussion of the answers afterwards

- Reading the class. A class room at 9am on a Monday morning behaves differently than the same group after lunch on a weekday.

The use of the classroom quiz had an overall positive affect on the student performance which is supported by Braun et al. [11] who state that participation and activities in classroom are key areas which should be addressed. The classroom quiz used applied knowledge in the classroom as suggested by Brown et al. [16]. Davies [17] states that multiple choices alone is not sufficient for assessment which is why students were able to participate in classroom activities and more importantly participate in discussions to compliment the multiple choice quiz.
The importance of the quiz was not on the student's ability to answer the questions correctly, but rather on their willingness to participate. The real engagement happens when a significant portion of the students answer the questions incorrectly. This facilitates a dialogue between the students and the teacher as well as amongst students. The effect of this will draw in the entire class and further engage more passive students. As a result of this, it is recommended that there should be a degree of ambiguity to questions (or ambiguous multiple choice answers). This is contrary to the recommendations of [12], however, the outcome will identify students who are simply guessing the answer as well as increasing attention to what is being asked. Feedback from the teacher will create a natural dialogue (one that can often be missing) with the group and therefore enhance the learning experience of the entire group.

The outcome of the enhanced classroom activity could then be shown to benefit their learning when a graded continuous assessment was taken. Although it did not appear that engagement with the learning material increased, classroom engagement and assessment performance did increase. In addition to the results shown above, a new cohort is currently undergoing the same module. The new cohort has had the benefit of the classroom quiz from the beginning. Preliminary results are marginally above the ones shown in section 4. However, this time there is a noticeable difference in the number of students engaging with the material on a regular weekly basis.

As an added incentive to improve engagement in the classroom quiz students could be rewarded with partial credit. By tracking student number login for the Socrative [20] quiz, students could be awarded a percentage of their CA for participation. This however, would remove some of the anonymity amongst peers if they are familiar another student number. However, it is assumed that awarding marks for participation in the quiz rather than performance would encourage student engagement.

As discussed in section 2, the authors of [13] identify 5 key ingredients to aid in student motivation. The authors do not emphasise any of the ingredient as being more significant than another. However, we would contend that there are some ingredients that are more influential than others. The following diagram (see Figure 6) places the Teacher at the center and as the most significant items in our approach. The teacher is the driving force and their enthusiasm to adapt to the situation will drive the success. The next significant item was the environment. To put simply, if the conditions do not allow for an interactive quiz then an alternative approach will need to be found (by the teacher). 


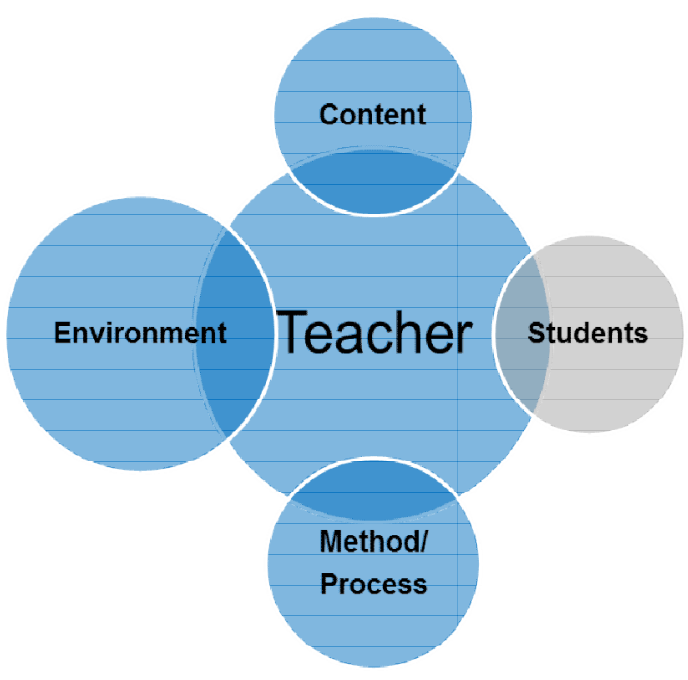

Figure 6. Interaction with students should place the Teacher at the center. Environment will also dictate the nature of the interaction

In Figure 6 the student is greyed out and is of a lesser significance. The reason for this is that the teacher has little control of the selection of the students from one cohort to the next. In addition to this, their frame of mind can vary significantly depending on the time of the scheduled class.

\section{References}

[1] Carnine, S., Kame'enui, T., (2004). Direct Instruction Reading ( $4^{\text {th }}$ Edition), p11. Pearson Education.

[2]Hovious, A., (2013). Reality Check: Sage on the Stage Vs. Guide on the Side, http://designerlibrarian.wordpress. com/2013/05/24/reality-check-sage-on-the-stage-vs-guideon-the-side/

[3] Columbia University CTL, The Center for Teaching and Learning, (2014). Progressive Pedagogies [Fact sheet].http://www.columbia.edu/ $\mathrm{cu} /$ tat/pdfs/progressive.pdf

[4]Lage, M., J., Platt, G., J., \& Treglia, M., (2000). Inverting the classroom: A gateway to creating an inclusive learning environment. The Journal of Economic Education, 31(1), 30-43.

[5] O'Farrell, C., (2005). Enhancing Student Learning through Assessment. http://www.tcd.ie/CAPSL/Academic practice/worddocs/assessment_toolkit. Access Date: 18th December, 2014.
[6] Palmer, D., (2007). What Is the Best Way to Motivate Students in Science? Teaching Science-The Journal of the Australian Science Teachers Association, 53(1), 38-42.

[7] Debnath, S., C., (2005). College Student Motivation: An Interdisciplinary Approach to an Integrated Learning Systems Model. Journal of Behavioral and Applied Management, 6(3), 168-189.

[8] Gillentine, A., and Schulz, J., (2001). Marketing the Fantasy Football League: Utilization of Simulation to Enhance Sport Marketing Concepts.Journal of Marketing Education, 23(3), 178-187.

[9] Heitzmann, R., (2010). 10 Suggestions for Enhancing Lecturing.Education Digest, 75(9), 50-54.

[10] Bunce, D., M., Flens, E. A., and Neiles, K. Y. (2010). How Long Can Students Pay Attention in Class? A Study of Student Attention Decline Using Clickers

[11] Braun, K., W., and Sellers, R., D., (2012). Using a "daily motivational quiz" to increase student preparation, attendance, and participation. Issues in Accounting Education, 27(1), 267-279.

[12] Trugman, H., (2007). The Role of Tests in Students (De)Motivation. Publications by Betaiatefl, January 1

[13] Williams, K., C., and Williams, C., C., (2011). Five key ingredients for improving student motivation. Research in Higher Education Journal, 12, 1-23.

[14] Biggs, G., \& Tang, C., (2011). Teaching for Quality Learning at University. Maidenhead: McGraw-Hill and Open University Press.

[15] ISSE, (2013). The Irish Survey of Student Engagement (ISSE) Implementation of the 2013 National Pilot. http://studentsurvey.ie/wordpress/wp-content/ uploads/2013/12/ISSE_Survey_final2013.pdf. Access Date: $18^{\text {th }}$ December, 2014.

[16] Brown, G., Bull, J., and Pendlebury, M., (2013). Assessing student learning in higher education.

[17] Davies, P., (2001). Computer Aided Assessment MUST be more than multiple-choice tests for it to be academically credible?

[18] Cisco System Inc. (2015) Cisco Networking Academy. https://www.netacad.com/. Access Date: $15^{\mathrm{th}}$ February. 2015.

[19] Blackboard, (2015). Blackboard Inc.http://uki. blackboard.com/sites/international/globalmaster/Platforms/ Blackboard-Learn.html. Access Date: 15th February, 2015.

[20] Socrative.com, (2015). Socrative by MasteryConnect. http://www.socrative.com/ Access Date: $15^{\text {th }}$ February, 2015. 